\title{
Tests of the separate retrieval of item and associative information using a frequency-judgment task
}

\author{
WILLLAM E. HOCKLEY \\ Wilfrid Laurier University, Waterloo, Ontario, Canada \\ and \\ CAROLINA CRISTI \\ University of Western Ontario, London, Ontario, Canada
}

\begin{abstract}
The degree to which item and associative information can be distinguished at retrieval was assessed using a frequency-judgment task. Words were shown various numbers of times individually and as members of word pairs. At test, subjects judged the frequency of the word pairs and a word's frequency as an individual item, its frequency as a member of word pairs, or the combined frequency of the word. Subjects made all of these judgments with considerable accuracy. The frequency of presentations in the nontarget format had consistent, but small, effects on the judgments for the target frequencies. The results provide further support for the distinction between item and associative information and for the source-monitoring framework of Johnson, Hashtroudi, and Lindsay (1993), and they have important implications for global matching models of memory.
\end{abstract}

Item information, the representation of the occurrence of a single event, and associative information, the representation of relationships between individual items, have been distinguished both empirically and theoretically. Empirically, recent evidence has shown that recognition memory for item and associative information have different time courses at retrieval (Dosher, 1988; Gronlund \& Ratcliff, 1989), have different rates of forgetting (Hockley 1991b, 1992; Murdock \& Hockley, 1989), and are differentially affected by natural language word frequency (Clark, 1992; Clark \& Burchett, 1994; Clark \& Shiffrin, 1992; Hockley, 1994). Recent neurophysiological evidence also supports this distinction and indicates that the hippocampal region plays a fundamental and specialized role in associative learning (Eichenbaum \& Bunsey, 1995).

From a theoretical perspective, the distinction between item and associative information has been formally instantiated, although in quite different ways, in the family of global matching models. The common assumption within

\footnotetext{
This work was supported by a Natural Sciences and Engineering Research Council of Canada operating grant and a course remission grant from Wilfrid Laurier University to the first author, and an NSERC summer research scholarship awarded to the second author, who is now at the University of Ottawa. We thank Doug Hintzman, Doug Nelson, and Scott Gronlund for many constructive comments on an earlier version of this paper, including suggestions that led to Experiments 5 and 7 . We also thank Mike Humphreys for his question at a presentation of a portion of this work at the 1994 meeting of the Psychonomic Society in St. Louis, which led to Experiment 6, and Joanne Bonanno and Sarah Mercer for assistance in data collection. Correspondence can be addressed to W. E. Hockley, Department of Psychology, Wilfrid Laurier University, Waterloo, ON, Canada N2L 3C5 (e-mail: whockley@ machl.wlu.ca).
}

this class of models is that, at test, the output of the model is a familiarity value that represents the global match of the recognition probe (a single item or a pair of items) and the contents of memory. Three representatives of this family are MINERVA 2 (Hintzman, 1984, 1988), the search of associative memory (SAM) model (Gillund \& Shiffrin, 1984; Raaijmakers \& Shiffrin, 1981), and Murdock's $(1982,1993)$ theory of distributed associative memory (TODAM) model.

In the SAM model, memory is represented as a matrix of strengths of connections between stored items, or images, and cues used to probe memory. The retrieval-cue set consists of the test item or items and context information. Associative information is represented by the strength of the connections between the memory items or images. Item recognition is based on a global familiarity value derived from the product of the strengths of connection of the retrieval-cue set to an image, summed over all images in memory. The global familiarity of associative information (i.e., recognition of a pair of items) is given by multiplying the strength of connection of each member of the pair to a given image and the strength of connection of the context cue to the same image, and summing these products over all the images in memory. Both item (self-strength) and associative information (interitem strength) contribute to the overall familiarity values calculated for item and associative recognition decisions.

In MINERVA 2 there is a separate trace for every encoded event. Each item is represented by a vector of features (each feature taking the value of $-1,0$, or +1 ). The features of the item vectors represent both content and context elements. Associations between pairs of items are represented by concatenating the item vectors of the pairs. 
Both item and associative recognition decisions are based on a comparison of the vector representing the probe and all vectors stored in memory, which results in an echo intensity, or a global familiarity, value. Specifically, each feature of the probe vector is multiplied with the corresponding feature of each trace in memory, and these products are summed over all features. The sum is normalized by the number of features that are nonzero in both the probe and the memory trace, and then cubed (which increases the signal-to-noise ratio of the target trace relative to nontarget traces). This results in an activation value for each trace, and these values are summed over all traces in memory.

TODAM also uses vectors of random features to represent item and associative information. In contrast to both SAM and MINERVA 2, all information is stored in one composite memory vector. Item information is encoded by adding a vector representing the item to the common memory vector. To represent an association between a pair of items, the two item vectors are combined by convolution to produce a new vector, and this vector is also added to the memory vector. Each element of the composite memory vector is, therefore, the sum of the appropriate elements of the different input vectors.

Item recognition in TODAM is based on the dot product of the vector representing the test probe with the memory vector. The dot product represents the degree of match, or global familiarity, between the probe and one or more traces making up the memory vector. For associative recognition, the vectors representing the individual items of the test probe are convolved and the dot product of the convolved vector with the memory vector is computed.

In MINERVA 2, item and associative information are encoded and stored together as associative information is represented by the concatenation of the individual item vectors. In TODAM, item and associative information are stored together in a common memory vector, but these two types of information are separate in that the individual item vectors are independent and the convolved vector representing an association between two items is orthogonal to both of the individual item vectors. Moreover, the relative strength or amount of each type of information can vary. Thus, item and associative information are assumed to be separately encoded and can be separately retrieved. Finally, in the SAM model, item and associative information are assumed to be separately encoded and represented in memory, but both item and associative information are retrieved together as both types of information contribute to the global familiarity of item and associative recognition probes. (A more detailed comparison of these models and their application to item and associative recognition is provided by Clark \& Shiffrin, 1992, and Humphreys, Pike, Bain, \& Tehan, 1989.)

Global matching models therefore make different assumptions concerning the nature and the degree of independence of item and associative information. Thus, determining the extent to which these two types of information are separately encoded and retrieved would provide an important basis for comparing these models.

Hockley and Cristi (1996) attempted to evaluate the degree to which item and associative information were separately encoded. In their procedure, subjects studied pairs of random words and were instructed to emphasize either item or associative information. Immediate recognition tests reinforced memory for the emphasized information. In an unexpected final recognition test, all subjects were tested on both types of information. If item and associative information were encoded separately, then the time spent encoding one type of information should be at the expense of encoding the other type of information. That is, there should be a tradeoff at encoding between item and associative information.

Hockley and Cristi found that when subjects emphasized item information at encoding, their subsequent recognition memory for associations between items was quite poor. When associative information was emphasized, recognition memory for associations improved markedly but recognition memory for item information did not reliably differ from the item-recognition performance of those subjects who emphasized only item information. Emphasizing associative information, therefore, did not diminish or reduce the encoding of item information. Hockley and Cristi concluded that either item and associative information are encoded together (as is assumed in MINERVA 2) or, if they are encoded separately, both types of information are summed or combined at retrieval (as is assumed in the SAM model).

The present study was designed to determine the degree to which subjects can differentially retrieve item and associative information. A frequency-judgment task was used to assess how well subjects could distinguish between separate occurrences of single words (item information) and word pairs (associative information) when the single words also appeared as members of word pairs. This approach is similar to that used by Hock, Malcus, and Hasher (1986), who showed that subjects could discriminate the frequencies of letters independently of the frequencies of the four-letter strings in which the letters were presented. Hock et al. concluded that both global-level (letter strings) and element-level (letters) units were stored in memory. Expressed in different terms, their results provide evidence for the separate retrieval of item (letters) and associative (letter strings) information.

In the first four experiments of the present study, subjects studied both single words and pairs of words that occurred various numbers of times in the study list. Two conditions were compared. In the joint condition, words shown singly (singletons) also appeared as members of word pairs. In the disjoint condition, singletons were not members of word pairs. At test, subjects separately estimated the study-list frequency of singletons and word pairs.

In the TODAM model, item and associative information are assumed to be separately encoded and retrieved. This assumption leads to the prediction that frequency judgments for word pairs should not differ in the joint 
and disjoint conditions, because item information should not influence the retrieval of associative information. It is, however, usually assumed in TODAM that both item and associative information are encoded when a pair of words are studied together, although the relative strength or amount of each type of information could vary. This assumption would predict that frequency judgments for singletons would be greater in the joint condition than in the disjoint condition, because item information encoded from pair presentations would contribute to the familiarity of the single words.

In MINERVA 2, a single-item probe would match the representations of that item in memory, and it would also partially match the representations of a pair of items that included that item as a member. In the SAM model, item and associative information are combined at retrieval in the assessment of the familiarity of both single-item and word-pair probes. Thus, MINERVA 2 and SAM could both predict that subjects would give higher frequency estimates for singletons and word pairs in the joint condition relative to the disjoint condition, because frequency judgments in the joint condition would be based on, or influenced by, the total number of occurrences of the items in the study list.

It should be noted, though, that the above predictions do not take into account the role of contextual information that is a feature of both MINERVA 2 and SAM. A more complete discussion of these models is presented in the General Discussion when they are reconsidered in light of the results of the following experiments.

\section{EXPERIMENT 1}

In the study lists for the joint condition, singletons shown once were included as a member of a pair presented five times, singletons shown three times appeared as a member of a pair that occurred three times, and singletons shown five times were part of a pair presented once. Thus, in the joint condition, the sum of the number of occurrences of words shown both singly and in a pair was always six. In the study lists for the disjoint condition, singletons and word pairs were also shown one, three, or five times but singletons were not members of word pairs. At test, subjects in both conditions separately estimated the frequency of singleton and word-pair presentations.

\section{Method}

Subjects. Twenty undergraduate students were randomly assigned to the joint condition and 20 were assigned to the disjoint condition. The students received course credit for participation.

Apparatus and Stimuli. In all experiments, list generation, presentation, and response recording were controlled by personal computers. The keyboards were fitted with opaque plastic covers that exposed only the labeled response keys.

The word pool used in all experiments consisted of 480 concrete nouns derived from Paivio, Yuille, and Madigan (1968). All words had an imageability rating of 5.0 or above based on the Paivio et al. norms, where words were rated from 1 to 7 .

Procedure. There were four study-test cycles in a session. In the disjoint condition, study lists consisted of four single words and four word pairs presented at each of the frequencies of one, three, and five. All of the occurrences of two of the singletons and two of the word pairs at each frequency were in the first half of the study list, and all of the occurrences of the other two words and word pairs were in the second half of the study list. The order of presentations in each half of the study lists was random. There were also one singleton and one word pair added to the beginning and end of the list to absorb primacy and recency effects. Thus, there was a total of 76 presentations in the study lists.

The study lists in the joint condition were constructed in the same fashion except that singletons shown once also appeared as one member of a word pair presented five times, singletons shown three times were included as one member of a pair presented three times, and singletons shown five times were part of a pair presented once. Only one member of each pair was a singleton. In each half of the study list, singletons occurred once as a left-hand member and once as a right-hand member of a study pair at each frequency.

In both the joint and disjoint conditions, word pairs were shown for $3 \mathrm{sec}$ and singletons were shown for $1.5 \mathrm{sec}$ in order to equate presentation time per item. There was a blank interval of $1 \mathrm{sec}$ between presentations. An absolute frequency-judgment test, signaled by the cue "? FREQUENCY ?" shown for $3 \mathrm{sec}$, followed each study list.

In both conditions, the test list consisted of the 12 singletons and the 12 word pairs from the study list presented in random order. For each single-word test probe, the subjects pressed one of six response keys to indicate the number of times that the word had occurred as a singleton in the study list. For word-pair tests, the subjects indicated the number of times that the pair had been shown in the study list. The $\mathrm{R}, \mathrm{T}, \mathrm{Y}, \mathrm{U}, \mathrm{I}$, and $\mathrm{O}$ keys, labeled from 1 to 6 , were used as the response keys. The test was subject paced, with a $1-\sec$ interval between a response and the subsequent test probe.

At the beginning of the session, all subjects were fully informed of the nature of the task, and those in the joint condition were told that singletons would also appear in word pairs. It was emphasized that they should try to remember the number of times singletons appeared by themselves and not to include in their frequency estimates the number of times that singletons also occurred as a member of a pair. The subjects were not informed of the actual presentation frequencies. All subjects were also encouraged to use interactive imagery or sentence-generation strategies for word pairs in order to form an association between the items of each pair.

\section{Results and Discussion}

Mean frequency estimates were calculated for every subject in each condition. The data were subjected to a 2 (joint vs. disjoint condition) $\times 2$ (singletons vs. pairs) $\times 3$ (frequency) mixed factorial analysis of variance (ANOVA). The .05 level of reliability was adopted for all statistical comparisons.

Mean frequency judgments for each condition as a function of presentation frequency are given in the left panel of Figure 1 for singletons and in the right panel for word pairs. The inset in Figure 1 shows the expected pattern of results for singletons in the joint and disjoint conditions if frequency judgments were based on the combined number of occurrences of the word (i.e., the sum of both singleton and word-pair frequencies).

The main effects of frequency $[F(2,76)=514.5$, $\left.M S_{\mathrm{e}}=.29\right]$ and stimulus type (words vs. pairs) $[F(1,38)=$ $\left.6.1, M S_{\mathrm{e}}=1.50\right]$ and their interaction $[F(2,76)=49.9$, $\left.M S_{\mathrm{e}}=.11\right]$ were significant. The main effect of condition (joint vs. disjoint) was not reliable $[F(1,38)=2.6$, $\left.M S_{\mathrm{e}}=.91\right]$, but the interactions between condition and 


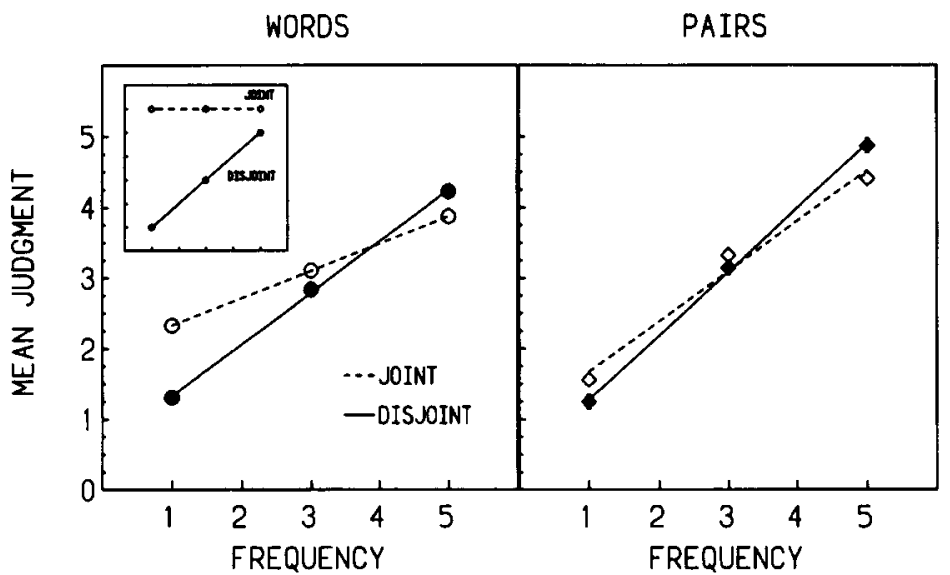

Figure 1. Mean frequency judgments as a function of presentation frequency for single words (left panel) and word pairs (right panel) for the joint and disjoint conditions of Experiment 1 . The inset figure shows the predicted pattern for single words if frequency judgments were based on the total number of occurrences of the words.

frequency $\left[F(2,76)=22.6, M S_{\mathrm{e}}=.29\right]$, condition and stimulus type $\left[F(1,38)=7.7, M S_{\mathrm{e}}=.20\right]$, and condition, frequency, and stimulus type $\left[F(2,76)=6.4, M S_{\mathrm{e}}=.11\right]$ were all significant. As can be seen in Figure 1, mean estimates were more accurate in the disjoint condition than in the joint condition, and the difference between the conditions was greater for singletons than for word pairs.

The results of Experiment 1 show that presenting singletons in word pairs reduces the accuracy of frequency judgments more for singletons than for word pairs. Presenting singletons in word pairs, however, increased the frequency estimates of the singletons only at the lowest frequency. Moreover, in absolute terms, this effect was to increase mean frequency estimates by only one despite the fact that the singletons presented once were also members of pairs that were shown five times.

\section{EXPERIMENT 2}

Experiment 2 was designed to replicate Experiment 1 with a within-subject comparison of the joint and disjoint conditions.

\footnotetext{
Method

Subjects. Twenty-five undergraduate students participated for course credit or for payment.

Procedure. There were five study-test cycles in each session. In each half of the study lists, one word and one word pair were shown at each of the frequencies of one, three, and five. There was no overlap between the words in these disjoint presentations. The joint presentations were constructed in the same manner as in Experiment 1. In each half of the study lists, one word appeared once alone and as a member of a pair that occurred five times, one word was shown three times alone and in a pair presented three times, and one word occurred five times alone and in a pair shown once. The order of presentations in each half of the study lists was random. An additional single word and word pair were added to the beginning and the end of the lists to serve as buffers. Thus, there were a total of 76 presentations in every study list.
}

The test list consisted of 12 singletons and 12 word pairs. The order of presentation was random and the test was subject paced. Subjects responded in the same manner as in Experiment 1. They were asked to try to remember the number of times words were shown alone and the number of times the word pairs occurred in the study list. They were told that some of the single words also appeared as members of word pairs, but that they should try to keep singleton and word-pair frequencies separate. In all other respects, the procedure was the same as in Experiment 1.

\section{Results and Discussion}

Mean judgments as a function of frequency for each condition are shown in Figure 2. An ANOVA based on subject mean estimates showed that the main effects of frequency $\left[F(2,48)=311.6, M S_{\mathrm{e}}=.57\right]$, condition (joint vs. disjoint) $\left[F(1,24)=16.7, M S_{\mathrm{e}}=.16\right]$, and stimulus type (singletons vs. pairs) $\left[F(1,24)=15.3, M S_{\mathrm{e}}=.35\right]$ were all reliable. The main effects were qualified by significant interactions between frequency and type of stimulus $\left[F(2,48)=32.5, M S_{\mathrm{e}}=.14\right]$, frequency and condition $\left[F(2,48)=9.4, M S_{\mathrm{e}}=.17\right]$, and frequency, stimulus type, and condition $\left[F(2,48)=3.5, M S_{\mathrm{e}}=.08\right]$.

The results of Experiment 2 are very similar to the pattern of results obtained in Experiment 1. Both experiments showed that the accuracy of frequency judgments is greater in the disjoint than in the joint condition, and that the difference between these conditions is greater for judgments for singletons than for word pairs. The difference between the joint and disjoint conditions is, in absolute terms, very modest, and far less than what would be expected if frequency judgments for singletons and word pairs in the joint condition were based on the combined number of occurrences of the words.

\section{EXPERIMENT 3}

In Experiments 1 and 2, subjects used a response scale that varied from 1 to 6 to estimate frequency. Thus, they 


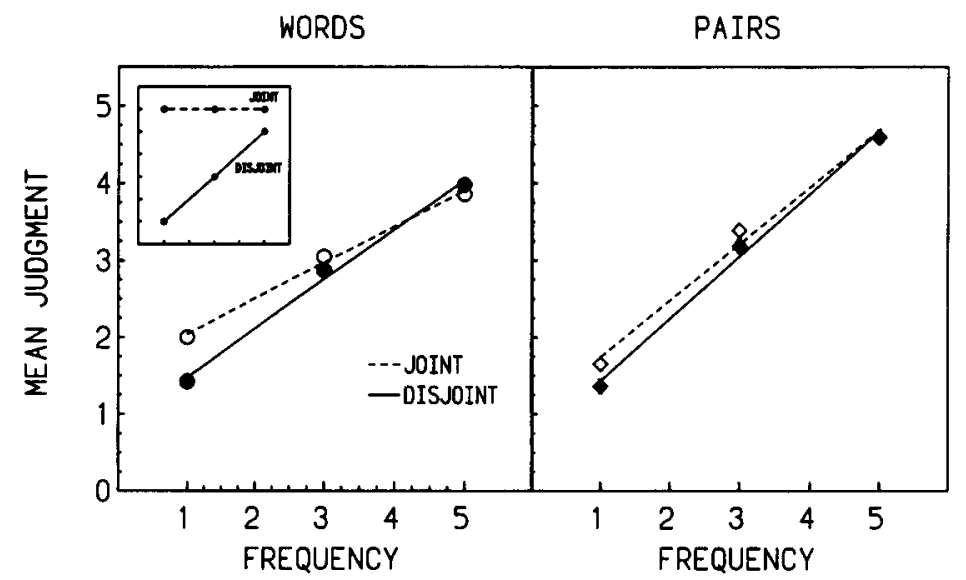

Figure 2. Mean frequency judgments as a function of actual frequency for single words (left panel) and word pairs (right panel) for the joint and disjoint conditions of Experiment 2 . The inset figure shows the expected pattern if frequency judgments for single words were based on the total number of presentations of the words.

could not give a " 0 " (new) response to words or pairs that they did not recognize. It is possible that at least some of the differences between the mean frequency estimates in the joint and disjoint conditions could be due to the fact that subjects would be less likely to recognize all words in the disjoint condition, especially words that occurred only once. In Experiment 3, subjects responded on a scale that ranged from 0 to 5 and new items and new pairs were included in the test list. Also, in the joint condition, all possible frequency combinations of words appearing both as singletons and as members of word pairs were represented in the study lists.

\section{Method}

Subjects. Twenty-nine undergraduate students participated for course credit.

Procedure. There were five study-test cycles in a session. Study lists consisted of a total of 60 presentations (including two buffers added to the beginning and to the end of each list). The disjoint condition was represented by one singleton and one pair shown at each of the frequencies of one, two, and four. The joint condition was represented by three singletons and three word pairs shown at each of the possible frequencies. Of the three singletons shown once, one was as a member of a pair that occurred once, one was a member of a pair presented twice, and one was a member of a pair that appeared four times. The same was true for the singletons shown two and four times. The order of the presentations in the study lists was random.

The test list following each study list consisted of the 12 singletons, the 12 word pairs, 4 new words, and 4 new pairs, presented in random order. The new word pairs consisted of two words not previously shown. In all other respects, the procedure was the same as in Experiment 2.

\section{Results and Discussion}

Subjects accurately identified new single words (.91) and new pairs (.93). Mean frequency judgments for new words and new pairs were .14 and .13 , respectively. Mean frequency estimates for old singletons and old word pairs were calculated, excluding " 0 " frequency responses. This was done in order to compare frequency judgments only for stimuli that subjects recognized as old. These mean estimates are shown as a function of actual frequency in Figure 3 . For the joint condition, the single words are distinguished by the frequency with which they also appeared as members of pairs, and the word pairs are differentiated by the frequency with which the member of the pair appeared as a single word. The inset figure shows the predicted results if the frequency judgments had been based on the combined number of occurrences of the words.

The mean estimates were analyzed in a 3 (frequency: $1,2$, and 4$) \times 4$ (condition or number of overlapping presentations: $0,1,2$, and 4 ) $\times 2$ (singletons vs. pairs) withinsubjects ANOVA. The main effects of actual frequency $\left[F(2,56)=280.3, M S_{\mathrm{e}}=.82\right]$, overlap condition $[F(3,84)$ $\left.=19.9, M S_{\mathrm{e}}=.21\right]$, and stimulus type $[F(1,28)=5.2$, $\left.M S_{\mathrm{e}}=.95\right]$ were all reliable. The main effects were qualified by significant interactions between frequency and condition $\left[F(6,168)=3.98, M S_{\mathrm{e}}=.15\right]$, frequency and type of stimulus $\left[F(2,56)=21.6, M S_{\mathrm{e}}=.29\right]$, and between frequency, condition, and stimulus type $[F(6,166)=$ $\left.2.8, M S_{\mathrm{e}}=.13\right]$.

As in the previous experiments, there was a reliable, although numerically small, difference between frequency estimates in the disjoint and joint conditions. This difference was greater at lower frequencies and greater for singletons than for word pairs. To assess the relative magnitude of the effects of actual frequency and overlap frequency on mean judgments, effect sizes were calculated. ${ }^{1}$ For singletons, the effect sizes for actual frequency and overlap frequency were .772 and .215 , respectively. For word pairs, the corresponding effect sizes were .861 and .177 . In both cases, the effect of actual frequency was much greater than the frequency of the overlapping presentations.

Another way to compare the relative magnitude of the effects of actual frequency and overlap frequency is to 


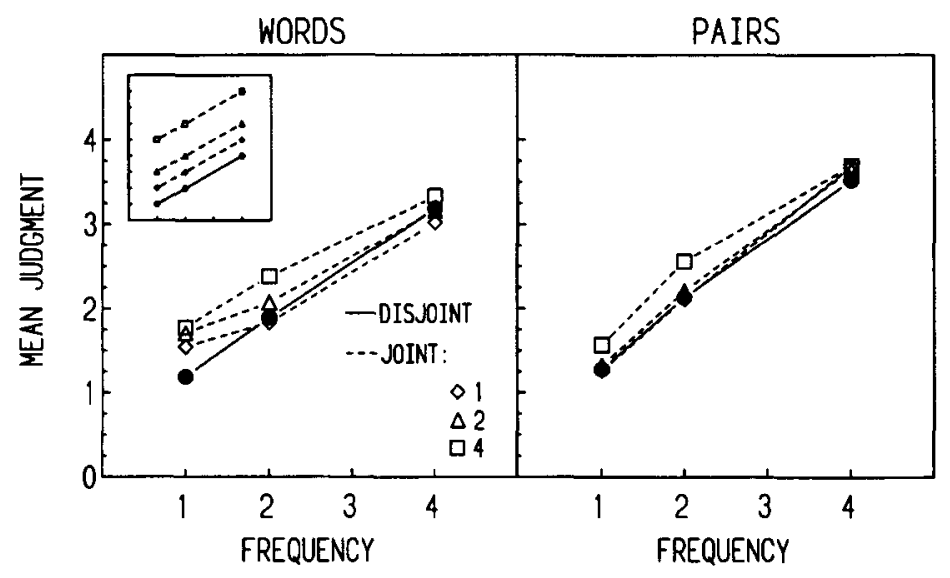

Figure 3. Mean frequency estimates as a function of actual frequency for single-word and word-pair presentations for the joint and disjoint conditions of Experiment 3. The inset shows the sum of the frequencies for words.

separately calculate the mean slopes of frequency estimates as a function of actual frequency and overlap frequency. For singletons, the mean slope of frequency estimates as a function of singleton frequency was .51, and the mean slope as a function of pair frequency was .12 . For word pairs, the mean slope of the estimates as a function of pair frequency was .75 , and the mean slope as a function of singleton frequency was .10. The individual slopes for each frequency condition are given in Appen$\operatorname{dix} \mathrm{A}$. For singletons, the overall ratio of the increase in mean estimates as function of singleton frequency compared with pair frequency was $.51: .12$, or 4.3 to 1 . The corresponding ratio for word pairs was $.75: .10$, or 7.5 to 1 .

To further compare the disjoint and joint conditions, the response distributions were calculated. The panels of Figure 4 show the proportion of each response separately for each of the singleton and word-pair frequencies. It can be readily seen in Figure 4 that the difference between the disjoint and joint distributions is greater for single words than for word pairs, and that the differences are greater at the lower frequencies. One aspect of these results should be emphasized--in both the disjoint and joint conditions, the response distributions peak at the correct frequency. Thus, while overlapping singletons in word pairs increased the variability of the frequency response distributions, it did not cause the modal responses to shift toward higher frequencies. In virtually all of the cases, the most frequent response was the correct response.

\section{EXPERIMENT 4}

In Experiments 1-3, the difference between frequency estimates in the joint and disjoint conditions was greater for singletons than for word pairs. In these experiments only one word of a pair was shown as a single item in the joint condition. Thus, subjects could have based their frequency judgments for pairs on the frequency of the member of the pair that was not presented as a single word. In Experiment 4, both words of a pair in the joint condition also appeared as single items.
In Experiment 3, the new, or distractor, pairs in the test list consisted of two new items. Thus, subjects could have based their " 0 " frequency (or recognition) decisions for word pairs on the familiarity of the individual members of the pairs. In Experiment 4, each distractor pair consisted of two words that were members of different study pairs. In Experiment 4, therefore, recognition of the word pairs had to be based on memory for the association between the two words formed at study and not on memory for the individual items.

Finally, in Experiments 1-3, the maximum frequency of singletons and word pairs was either four or five, which was close to the maximum frequency response of five or six. Subjects may not have given higher frequency estimates in the joint condition because they were reluctant to use the maximum response. In Experiment 4, actual frequency was varied from zero to three and subjects used the keys " $r$ " through " $p$," which were labeled from 0 to 6 , to respond. This allowed subjects to overestimate the higher frequencies without using the maximum-frequency response.

\section{Method}

Subjects. Forty undergraduate students participated for payment.

Procedure. There were five study-test cycles in a session. Study lists consisted of a total of 78 presentations, including two buffers both at the beginning and at the end of the lists. To represent the disjoint condition, one word and one pair were shown at each of the frequencies of one, two, and three. For the joint condition, three pairs were shown at each of the three frequencies. Both words of each pair at each frequency also appeared as singletons once, twice, or three times. Thus, in the joint condition, all possible frequency combinations of pairs and singletons were equally represented. Finally, an additional eight study pairs were shown once in the study lists; these pairs were used to construct four rearranged (or new) pairs for the test list. The order of all presentations in the study lists was random.

The test lists consisted of 32 presentations: 3 single words and 3 word pairs from the disjoint-study condition, 9 single words and 9 pairs from the joint condition, 4 new single words, and 4 rearranged word pairs. Each rearranged pair consisted of the right and left members of two different study-list pairs that were shown only once. Note that, in the joint condition, only one of the two words (selected 


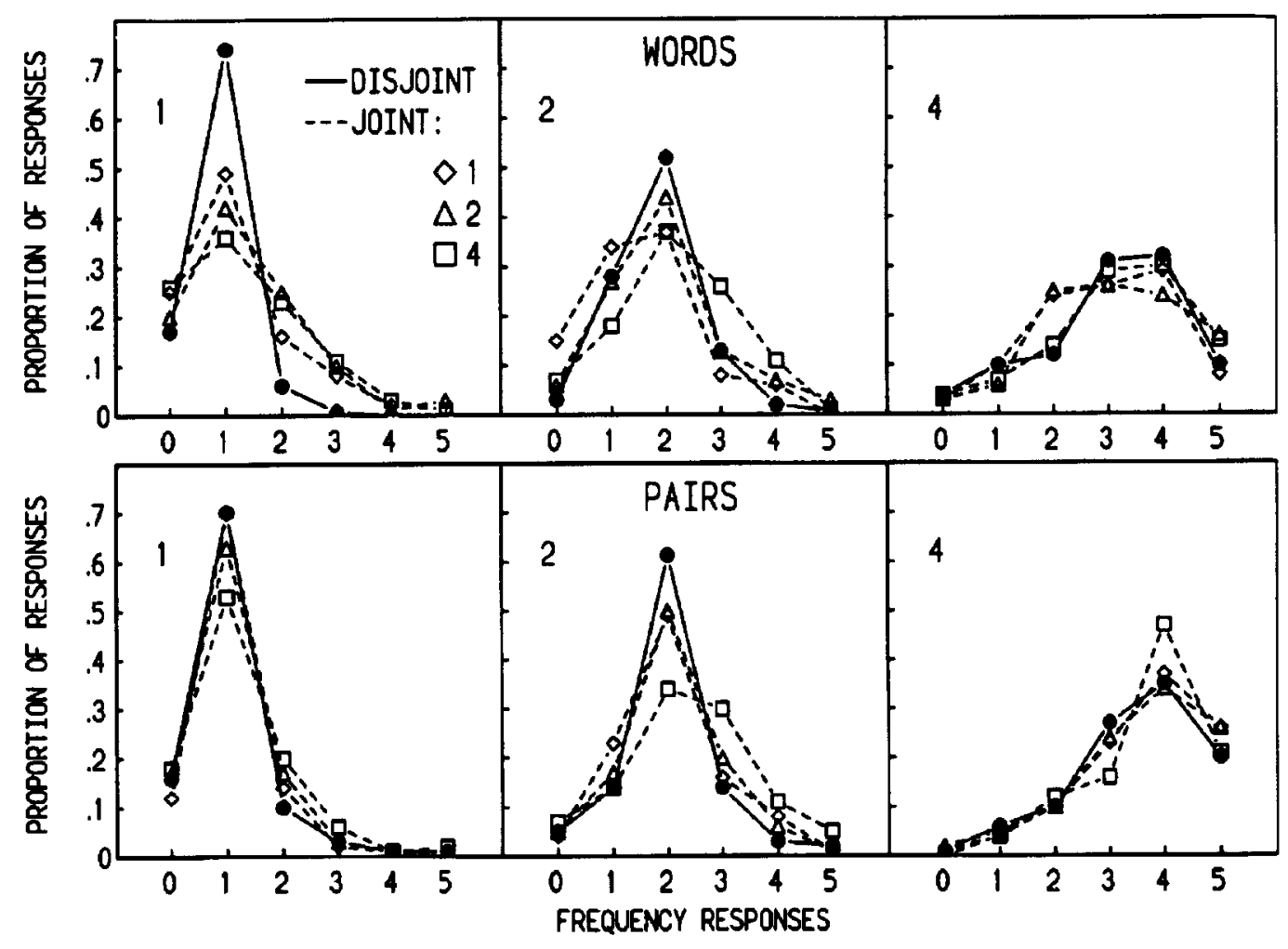

Figure 4. Frequency response distributions for single words (top panels) and word pairs (bottom panels) for Experiment 3 . The parameter is the actual, or correct, presentation frequency.

at random) from each word pair was tested as a single item. In all other respects, the procedure was the same as in Experiment 3.

\section{Results and Discussion}

The mean proportion of correct rejections (responses of "0") was .94 for new single words and .77 for rearranged pairs; the mean frequency estimates were .08 and .24 , respectively. Mean frequency estimates for old singletons and word pairs were calculated in the same fashion as in Experiment 3. That is, responses of " 0 " were excluded to restrict the analysis to the stimuli that the subjects recognized as old. Mean frequency estimates as a function of presentation frequency are shown in Figure 5.

Mean frequency estimates were analyzed in the same manner as described in Experiment 3. The main effects of actual frequency $\left[F(2,78)=61.5, M S_{\mathrm{e}}=.11\right]$, overlap condition $\left[F(3,87)=27.3, M S_{\mathrm{e}}=.05\right]$, and type of stimuli $\left[F(1,39)=27.3, M S_{\mathrm{e}}=.07\right]$ were reliable. The interactions between condition and frequency $[F(6,174)=$ $\left.5.4, M S_{\mathrm{e}}=.05\right]$ and stimulus type and frequency $[F(2,78)$ $\left.=2.2, M S_{\mathrm{e}}=.08\right]$ were also significant. For single words, the effect sizes for actual frequency and overlap frequency were .661 and .118 , respectively. For word pairs, the corresponding effect sizes were .624 and .213 .

The mean slope of the estimates for single words as a function of singleton frequency was .47 , and the mean slope as a function of pair frequency was .09. For word pairs, the mean slope of the estimates as a function of pair frequency was .77 and as a function of singleton frequency was .13. The individual slopes for each frequency condition are given in Appendix A. The overall ratio of the increase in mean judgments as a function of actual frequency compared with overlap frequency was $.47: .09$, or 5.2 to 1 , for single words and $.77: .13$, or 5.9 to 1 , for word pairs.

The response distributions showed the same pattern of results as was seen in Experiment 3 (see Figure 4). That is, the distributions peaked at the correct frequency and repeating singletons in word pairs did not cause the modal responses to shift toward higher frequencies.

Experiment 4 replicated the findings of Experiment 3 in all important respects. In addition, Experiment 4 showed that subjects do not overestimate frequency at the highest frequency in the joint condition as compared with the disjoint condition because they were reluctant to use the maximum responses.

\section{EXPERIMENT 5}

Experiments 1-4 demonstrate that subjects can, to a considerable degree, differentiate between the frequencies of words that occur individually and word pairs that include the singletons as members. It is not clear, however, to what extent this ability is dependent on encoding differences between singleton and word-pair presentations. Subjects were instructed to use different encoding strategies for singletons and word pairs which could serve to distinguish the same items in the single-word and wordpair study contexts. 


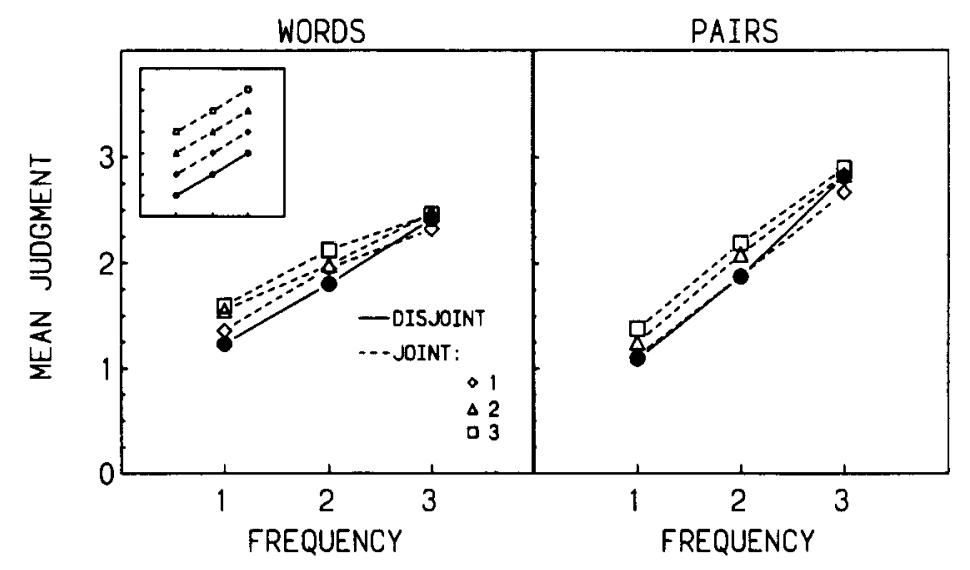

Figure 5. Mean frequency judgments as a function of actual frequency for single-word and word-pair presentations for the joint and disjoint conditions of Experiment 4. The inset figure shows the sum of the frequencies for words.

Experiment 5 was designed to determine whether repeating words in other pairs would have a greater effect on frequency estimates for word pairs. Therefore, in Experiment 5 , all study presentations were word pairs. Pairs representing the disjoint condition occurred one, two, or three times in the study list. Pairs representing the joint condition were also shown one, two, or three times, and the two words of these pairs also occurred in two different pairs shown one to three times. The design of Experiment 5 also afforded a comparison of frequency judgments for word pairs in which both members were repeated in other word pairs (joint pairs) with frequency judgments for word pairs in which only one member was repeated in another word pair (semijoint pairs).

\section{Method}

Subjects. Thirty-two psychology students participated for course credit.

Procedure. There were four different study-test cycles in a session. The study lists consisted of a total of 72 presentations of word pairs. The first two and last two pairs were buffer pairs. Three pairs, one shown once, one twice, and one three times, represented the disjoint condition. Nine pairs (three that occurred at each of frequencies one, two, and three) represented the joint condition. For each joint pair at each frequency (A-B pairs), both members of the pair were shown with a new partner (A-C and D-B pairs). The $A-C$ and $\mathrm{D}-\mathrm{B}$ pairs can be considered as semijoint pairs. For the three $\mathrm{A}-\mathrm{B}$ joint pairs shown once, there was an $\mathrm{A}-\mathrm{C}$ and a $\mathrm{D}-\mathrm{B}$ pair that occurred once, an A-C and D-B pair shown twice, and an $A-C$ and $D-B$ pair that occurred three times. The same was true for the three $\mathrm{A}-\mathrm{B}$ joint pairs shown twice and the three $\mathrm{A}-\mathrm{B}$ joint pairs that occurred three times. There were also eight different pairs shown once that were used to form four rearranged pairs in the test list. The order of the presentations in the study list was random. The study pairs were shown at a $3-\mathrm{sec}$ rate with a $\mathrm{I}-\mathrm{sec}$ interval between presentations.

The test lists consisted of the three disjoint pairs, the nine joint pairs $(\mathrm{A}-\mathrm{B})$, nine semijoint pairs $(\mathrm{A}-\mathrm{C}$ and $\mathrm{D}-\mathrm{B})$, and four rearranged pairs. The order of the 25 tests was random and the test was subject paced. Subjects made their frequency judgments by using the keys " $r$ " through " $p$," which were labeled from 0 to 6 .

\section{Results and Discussion}

The mean proportion of correct " 0 " responses for rearranged pairs was .73 , and the mean judgment of fre- quency for these pairs was .35 . In Figure 6, mean frequency estimates for the disjoint and joint pairs (excluding " 0 " responses) are shown in the left panel and mean frequency judgments for the semijoint pairs are shown in the right panel.

Inspection of Figure 6 indicates that repeating both members of a pair (joint pairs) has a greater effect on frequency judgments than does repeating only one member of a pair (semijoint pairs). This difference was confirmed in an analysis of the mean estimates. The main effects of frequency of the pair $\left[F(2,62)=293.3, M S_{\mathrm{e}}=.36\right]$, frequency of the word or words in another pair $[F(2,62)=$ $\left.39.0, M S_{\mathrm{e}}=.16\right]$, and joint versus semijoint pairs $[F(1,31)$ $\left.=33.4, M S_{\mathrm{e}}=.15\right]$ were all significant. In addition, the interactions between the frequency of a pair and the frequency of word(s) in another pair $[F(4,124)=10.1$, $\left.M S_{\mathrm{e}}=.15\right]$, frequency of the pair and joint versus semijoint pairs $\left[F(2,62)=16.1, M S_{\mathrm{e}}=.11\right]$, frequency of word(s) in another pair and joint versus semijoint pairs $\left[F(2,62)=8.2, M S_{\mathrm{e}}=.21\right]$, and the three-way interaction between these variables $\left[F(4,124)=5.04, M S_{\mathrm{e}}=.11\right]$ were also reliable. The effect sizes of actual frequency and overlap frequency were .854 and .363 , respectively, for joint pairs and .806 and .217 for semijoint pairs.

The mean slope of the estimates for joint pairs as a function of joint-pair frequency was .71 , and the mean slope as a function of semijoint-pair frequency was 23 . For semijoint pairs, the mean slope of the estimates as a function of semijoint-pair frequency was .78 and as a function of joint-pair frequency was .07 . (The separate slopes for each frequency condition are given in Appendix B.) The overall ratio of the increase in mean judgments as a function of actual frequency compared with overlap frequency was 3.1 to 1 for joint pairs and 11 to 1 for semijoint pairs.

Repeating members of a pair in other pairs had a reliable effect on frequency estimates for the word pairs. Furthermore, this effect was greater when both members of the pair were repeated in other pairs than when only one member of the pair was repeated. The magnitude of these effects is similar to the size of the effects of single- 


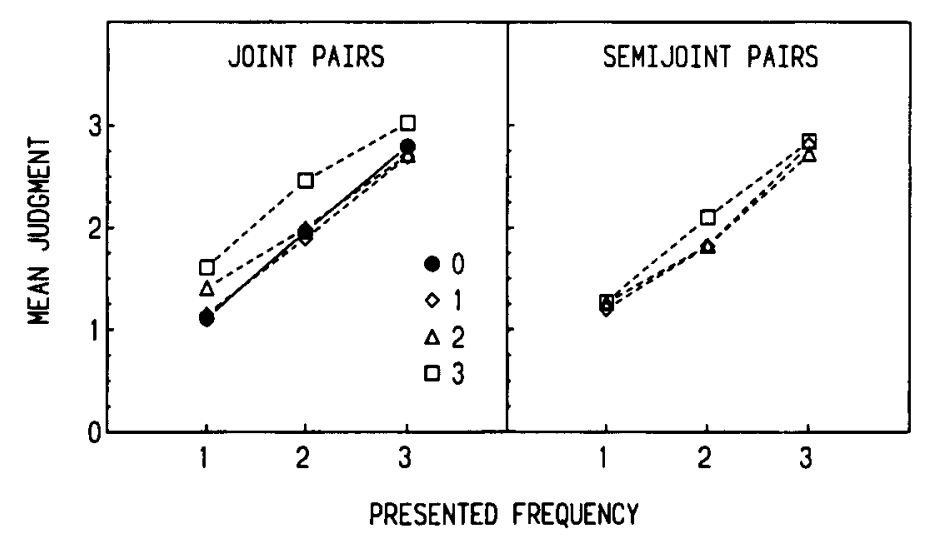

Figure 6. Mean frequency judgments as a function of actual frequency for joint pairs (both words repeated in other pairs) and semijoint pairs (one word repeated) for Experiment 5.

ton frequency on judgments for pairs, as found in Experiments $1-4$.

\section{EXPERIMENT 6}

Experiments 1-4 are uniformly consistent in that they show that subjects can, to a considerable extent, distinguish between the frequency of occurrence of singletons and word pairs when the singletons are also members of the word pairs. Can subjects also accurately estimate the total number of times that words appeared both as singletons and as members of word pairs?

Hockley and Cristi (1996) showed that item information is encoded when associative information is emphasized, and that recognition memory for the items does not measurably differ from that obtained when only item information is emphasized. Thus, subjects should be able to accurately estimate the frequency of occurrence of item information both when the items are presented as singletons and when they are members of word pairs. Such a finding would also make subjects' ability to largely restrict their frequency judgments to singleton presentations all the more impressive.

Experiment 6 was identical to Experiment 4 except for the instructions concerning the frequency estimates for single-word tests. In Experiment 6, subjects were instructed to estimate the combined number of times a single-word test probe was presented in the study list, both as a single word and as a member of a word pair.

\footnotetext{
Method

Subjects. Twenty-six students participated for course credit. Procedure. The procedure was identical to that of Experiment 4 except that for single-word test probes the subjects were instructed to estimate the total number of times the word had appeared in the study list regardless of whether it had been shown singly or as a member of a word pair. For word-pair test probes, the subjects were given the same instructions as in the previous experiments - that is, to estimate the number of times that pairs of words had been presented together in the study list. The subjects used the keys " $r$ " through "p," labeled 0 to 6 , to make their frequency judgments.
}

\section{Results and Discussion}

The mean proportion of correct rejections (frequency judgments of " 0 ") was .82 for new single words and .61 for rearranged pairs. The mean frequency judgments were .25 and .51 , respectively. Mean frequency estimates (excluding " 0 " responses) for old words and word pairs as a function of actual frequency are shown in Figure 7.

Mean judgments for words and pairs were analyzed separately. Frequency estimates for pairs showed the same pattern as in the previous experiments: Judgments increased with actual frequency $\left[F(2,50)=120.5, M S_{\mathrm{e}}=\right.$ $0.4]$, and repeating the members of pairs as single words had a significant, but more modest, effect $[F(3,75)=23.0$, $\left.M S_{\mathrm{e}}=0.2\right]$. The interaction between these variables was not reliable $\left[F(6,150)=1.5, M S_{\mathrm{e}}=0.2\right]$. The effect sizes for pair frequency and singleton frequency were .754 and .388 , respectively.

The mean slope of the estimates for word pairs as a function of pair frequency was .65, and the mean slope as a function of singleton frequency was .21 . (The separate slopes for each condition are given in Appendix A.) The overall ratio of the increase in mean judgments as a function of pair frequency to singleton frequency was 3.1 to 1 . These results are very similar to those observed for the joint pairs in Experiment 5.

For single-word tests, subjects had been instructed to estimate the combined number of occurrences of the words in the study list. As shown in the left panel of Figure 7 , mean judgments increased with singleton frequency and also increased systematically with the frequency of the words in word pairs. The main effects of frequency of singletons $\left[F(2,50)=67.2, M S_{\mathrm{e}}=0.4\right]$ and frequency of the word pairs $\left[F(3,75)=91.5, M S_{\mathrm{e}}=0.5\right]$ were highly reliable. The interaction between these factors did not approach significance $[F(6,150)<1]$. The effect sizes for singleton and word-pair frequency were .629 and .723 .

The mean slope of the estimates was .47 as a function of singleton frequency and .50 as a function of pair frequency. (The individual slopes for each frequency condition are given in Appendix A.) The overall ratio of the 


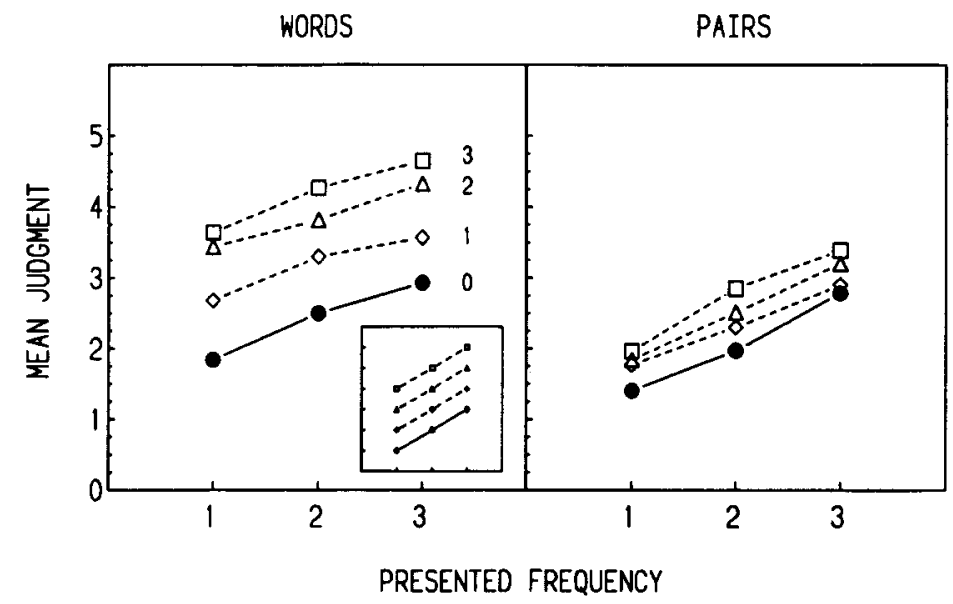

Figure 7. Mean frequency judgments for single words (left panel) and word pairs (right panel) for Experiment 6. The parameter indicates for words the number of presentations of the single words in word pairs, and for word pairs, the number of presentations of the members of the pair as single words. The inset figure shows the sum of the frequencies for the words.

increase in mean estimates as a function of singleton frequency to pair frequency was $.47: .50$, or .94 to 1 .

The response distributions for the frequency judgments for single-word tests are shown in Figure 8. The modal responses shift toward higher frequency judgments, both as a function of the frequency of words as single items and also as a function of the number of times the words were presented as a member of a word pair.

Experiment 6 demonstrates that subjects can, with quite reasonable accuracy, estimate the total number of times that words occurred at study when the words were shown both as single items and as members of word pairs. This result indicates that similar item information is encoded from singleton and word-pair presentations that can provide the basis for estimates of combined word frequency.

\section{EXPERIMENT 7}

In all of the previous experiments, subjects had been fully informed of the nature of the frequency tests and the subjects had completed four or five different study-test cycles. Thus, subjects could have adopted, or developed with practice, special strategies to separately encode item and associative frequencies. For example, subjects may have tried to keep a running count of presentations of words and used this count for word frequencies but based their pair-frequency estimates on the familiarity of the associative information. In Experiment 7, subjects studied a single list composed of word pairs and were not informed about the nature of the frequency test until after the study phase. One group of subjects was then instructed to esti-

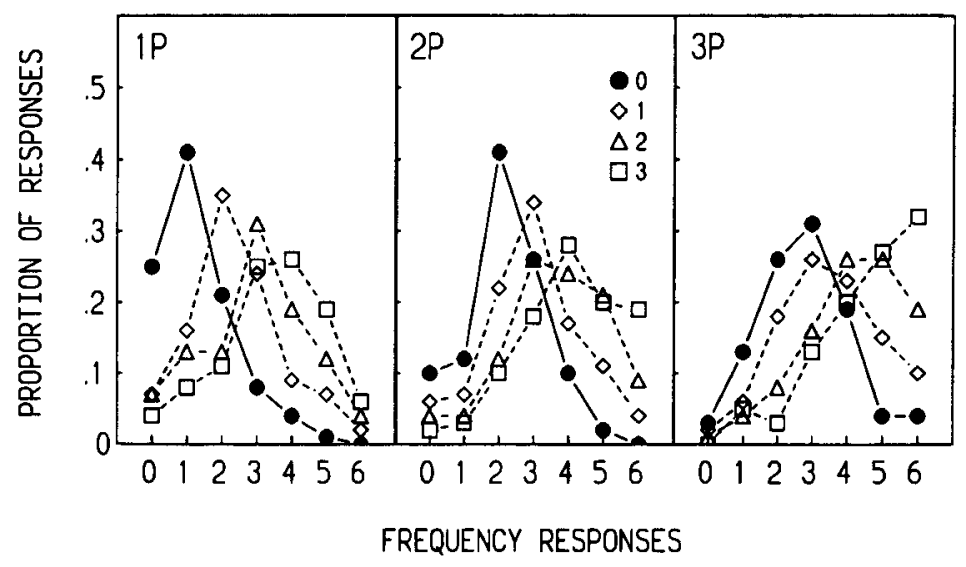

Figure 8. Frequency response distributions for words shown once (left panel), twice (middle panel), or three times (right panel) as single items in Experiment 6 . The parameter is the frequency of the words in word pairs. 
mate the frequency of word pairs; a second group was asked to estimate the frequency of single words. Thus, in Experiment 7, subjects had no reason to try to separately encode frequency information for items and pairs.

\section{Method}

Subjects. Seventy-six undergraduate students participated for course credit or for payment. There were 38 students in each frequencytest condition.

Procedure. The program used to generate the study lists for Experiment 5 was used, but only one list was shown. Each subject in the pair-frequency test group saw a different study list, and the same set of lists was presented to the subjects in the word-frequency test group.

All subjects were instructed to study the pairs by associating the two words in each pair and using interactive imagery or sentencegeneration strategies. They were told that a memory test for the associations would follow, but they were not given specific details concerning the nature of the test. After presentation of the study list, half of the subjects were instructed to estimate the total frequency of single words and half of the subjects were instructed to estimate the frequency of word pairs. Note that the frequency of the pairs varied from zero to three, whereas the frequency of individual words varied from zero to six because, in the joint condition, words were presented in joint pairs that were presented one to three times and in semijoint pairs that were presented one to three times.

In each condition, there were 25 tests presented in random order. The test was subject paced. In the pair-frequency test, the test list was the same as the test lists used in Experiment 5. That is, there were three disjoint pairs, nine joint $(\mathrm{A}-\mathrm{B})$ pairs, nine semijoint (A-C and D-B) pairs, and four rearranged pairs. In the single-word condition, the tests consisted of one word chosen randomly from each of the three disjoint study pairs, nine words selected randomly from each of the joint pairs (A-B), nine words (the $C$ and $D$ members) from the semijoint pairs ( $A-C$ and $D-B)$, and four new words. The subjects responded using the keys " $r$ " through " $p$," labeled from 0 to 6 .

At the end of the session, all subjects were asked if they had suspected that the test would involve memory for frequency. All of the subjects indicated that they had not considered such a possibility.

\section{Results and Discussion}

The mean proportion of correct " 0 " responses was .82 for new single words and .73 for rearranged (new) pairs. Mean frequency estimates for new single words and rearranged word pairs were .30 and .34 , respectively. Mean frequency judgments for words, joint pairs, and semijoint pairs (excluding "0" responses) are shown in separate panels in Figure 9. Mean frequency estimates for single words and word pairs were analyzed separately.

For single-word test probes, subjects were instructed to estimate the number of times the word had appeared as a member of a word pair together with the number of times the same word had appeared as a member of another word pair. The main effects of frequency of words in the joint pairs $\left[F(2,74)=45.8, M S_{\mathrm{e}}=1.41\right]$ and frequency of the words in other pairs $[F(3,111)=43.6$, $\left.M S_{\mathrm{e}}=1.40\right]$ were both highly significant. The interaction between these conditions was not reliable $[F(6,222)=$ $\left.1.83, M S_{\mathrm{e}}=1.17\right]$. The effect sizes for the frequency of the joint and semijoint pairs were .439 and .457 , respectively.

The mean slope of the estimates was .58 as a function of joint-pair frequency and .56 as a function of semijoint pair frequency. The slopes of the individual frequency conditions are given in Appendix B. The ratio of the increase in mean judgments as a function of joint-pair frequency to semijoint pair frequency was .58:.56, or approximately 1 to 1 .

The analysis of frequency judgments for the joint pairs showed that the main effects of actual frequency $[F(2,74)$ $\left.=145.5, M S_{\mathrm{e}}=1.24\right]$ and the frequency of other pairs $\left[F(3,111)=5.4, M S_{\mathrm{e}}=.98\right]$ were both significant. The interaction between these factors was not reliable $[F(6,222)$ $\left.=1.54, M S_{\mathrm{e}}=1.06\right]$.

In the final analysis, frequency judgments for joint pairs were compared with judgments for semijoint pairs. The main effects of actual frequency of the pair $[F(2,74)=$

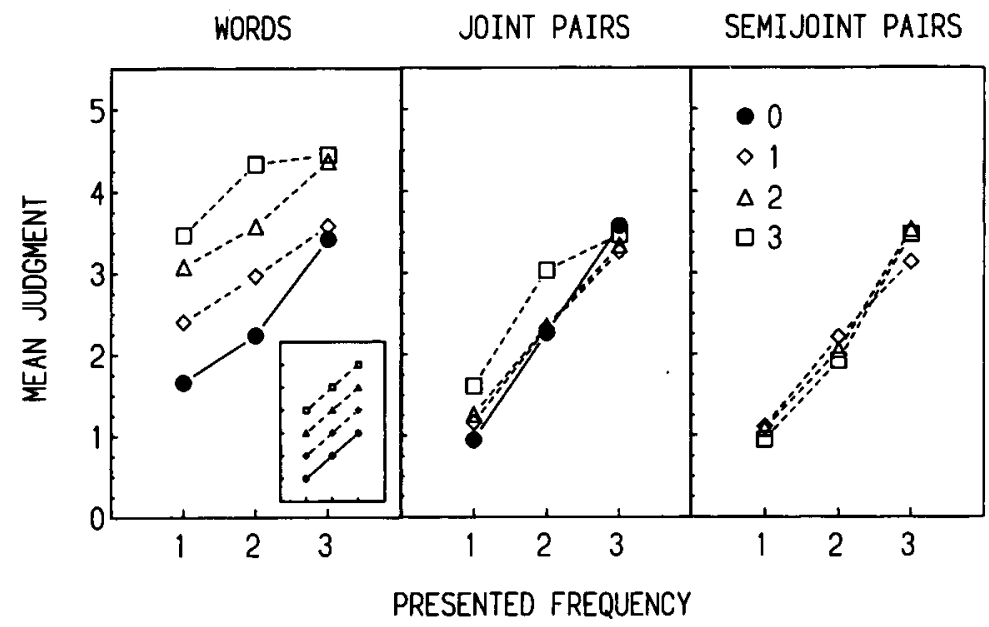

Figure 9. Mean frequency judgments for words (left panel), joint pairs (middle panel), and semijoint word pairs (right panel) for Experiment 7. The parameter represents the number of presentations of both members (joint pairs) or one member (semijoint pairs) of the word pair in other pairs. The inset figure shows the sum of the frequencies of the words. 
164.1, $\left.M S_{\mathrm{e}}=1.65\right]$, frequency of the word or words of the pair in another pair $\left[F(2,74)=5.8, M S_{\mathrm{e}}=.97\right]$, and joint versus semijoint pairs $\left[F(1,37)=43.83, M S_{\mathrm{e}}=\right.$ $0.54]$ were all significant. The main effects were qualified by significant interactions between the frequency of the pair and the frequency of word(s) in another pair $\left[F(4,148)=4.27, M S_{\mathrm{e}}=1.02\right]$, the frequency of the pair and joint versus semijoint pairs $\left[F(2,74)=11.96, M S_{\mathrm{e}}=\right.$ $.88]$, the frequency of word(s) in other pairs and joint versus semijoint pairs $\left[F(2,74)=4.7, M S_{\mathrm{e}}=.76\right]$, and the three-way interaction between these variables $[F(4,148)=$ $\left.3.38, M S_{\mathrm{e}}=.97\right]$. The effect sizes of pair frequency and overlap frequency were, respectively, .717 and .080 for joint pairs and .744 and .056 for semijoint pairs.

The mean slope of the estimates for joint pairs was 1.01 as a function of joint-pair frequency and .23 as a function of semijoint frequency. For semijoint pairs, the mean slope as a function of semijoint-pair frequency was 1.13 and the mean slope as a function of joint-pair frequency was -.03 . (The individual slopes for each frequency condition are given in Appendix B.) The ratio of the increase in mean judgments as a function of joint-pair frequency to semijoint-pair frequency was $1.0: .23$, or 4.3 to 1 , for joint pairs. Joint-pair frequency had very little effect on frequency judgments for semijoint pairs.

Experiment 7 replicated two important results under conditions in which subjects could not employ different or specialized encoding strategies for the frequencies of words and word pairs. First, frequency judgments for the sum of word presentations were reasonably accurate and reflected the occurrences of words in both the joint pairs and the semijoint pairs. The pattern of frequency judgments for single words shown in the left panel of Figure 9 is very similar to the pattern of frequency judgments for single words shown in Figure 7, where subjects estimated the combined frequency of words presented singly and as a member of a word pair. Thus, the results of both Experiments 5 and 7 demonstrate that subjects can judge the total frequency of words that occurred both alone and in pairs, or in different pairs.

Second, the results of Experiment 7 replicate the findings of Experiment 6, which showed that repeating members of a pair in another pair influences frequency judgments for the pair and that this effect is greater when both members, as opposed to only one member, of a pair are repeated. However, these effects are considerably smaller in magnitude when compared with the frequency estimates for the total number of word presentations.

\section{GENERAL DISCUSSION}

The degree to which item and associative information can be separately retrieved from memory was assessed by presenting words different numbers of times individually and as members of word pairs, and then asking subjects to separately estimate the frequency of occurrence of singletons and word pairs. Repeating members of word pairs as singletons or as members of other pairs had a consistent and reliable effect on frequency judgments for the word pairs. This effect was greater when both members, as opposed to only one member, of the pair were repeated. The sizes of these effects, however, were relatively modest in absolute terms. When both words of the pair were presented as singletons, the ratio of the mean slope of the frequency estimates as a function of pair frequency to the mean slope as a function of singleton frequency varied from 5.9 to 1 (Experiment 4) to 3.1 to 1 (Experiments 5 and 6). Averaged over Experiments 4-7, the mean ratio was 4 to 1 . Thus, frequency judgments of word pairs were, to a considerable degree, based on pair frequency.

Repeating singletons as members of word pairs also had a systematic and reliable effect on frequency judgments for the singletons. The absolute size of the effect was also quite modest. As illustrated in Experiments 1 and 2 , repeating a word shown once by itself and then in a word pair presented five times caused the mean frequency judgment for the single word to increase by about 1 . In Experiments 3 and 4, the ratios of the mean slope of the estimates as a function of singleton frequency to the mean slope as a function of pair frequency were 4.3 and 5.2 to 1 , respectively. Thus, frequency estimates for singletons were largely based on singleton frequency.

In Experiments 6 and 7, subjects judged the combined frequency of words that had occurred either singly and as a member of a word pair or presented in two different pairs, with varying frequencies. In both of these experiments, the ratios of the mean slopes of the frequency estimates as a function of singleton frequency to pair frequency or of joint-pair frequency to semijoint-pair frequency were approximately 1 to 1 . These results indicate that similar item information is encoded from both singleton and wordpair presentations that can support frequency judgments for the total number of occurrences of the items.

The fact that frequency judgments for words can include all occurrences of the words or be largely limited to singleton presentations is consistent with a variety of findings that demonstrate that the encoded representation of an item includes not only a description of the item itself but also information that defines the global and local context of the item. For example, studies have shown that subjects can remember in which list an item occurred (Anderson \& Bower, 1974; Hintzman, Block, \& Summers, 1973) and the temporal position of an item within a list (Hintzman \& Block, 1971). For items presented more than once, subjects can remember the positions at which an item occurred within a list (Hintzman \& Block, 1971), the temporal spacing between presentations in a list (Hintzman \& Block, 1973), and the frequencies of an item's presentations in each of two lists (Hintzman \& Block, 1971). As Anderson and Bower (1974) noted, "results have shown that subjects apparently store a relatively full 'description' of the input event, even under incidental learning conditions" (p. 509).

\section{Source Monitoring}

The results of Experiments 1-4 are also consistent with and complement Johnson, Hashtroudi, and Lindsay's (1993) theory of source of monitoring. Source monitor- 
ing refers to the ability to discriminate between externally derived information and internally generated information (or reality monitoring; Johnson \& Raye, 1981), to distinguish between different external sources of information, and to differentiate between internally generated sources of information. As described by Johnson et al. (1993), source monitoring is based on an assessment of the characteristics of memories. In their view, memories include records of perceptual, contextual, semantic, and affective information, as well as the cognitive operations that were performed when the memories were established. Such characteristics are used to determine the source of the memory. For example, subjects can distinguish between memories for items that were read and items that were generated, because memories for externally presented items contain more sensory information, whereas memories for internally generated items contain more information about the cognitive operations that occurred when the memories were formed (e.g., Johnson, Raye, Foley, \& Foley, 1981).

The present finding that subjects can distinguish between the presentation frequencies of single words and word pairs can be interpreted as reflecting successful source monitoring. The encoding operations involved in representing the occurrence of a word would differ from the operations involved in generating an association or relationship between a random pair of words. Thus, memories of the occurrences of single words and of word pairs would be expected to differ in terms of their contextual information and the cognitive operations that were performed at the time of encoding, and such differences could provide a basis for their discrimination.

Johnson, Taylor, and Raye (1977; Raye, Johnson, \& Taylor, 1980) used a frequency-judgment task to examine the ability to distinguish between seen and generated items. In their procedure, subjects both read cue-target word pairs (e.g., color-BLUE) that were shown two, five, or eight times and generated the same target items given the same cues two, five, or eight times. At test, subjects were asked to estimate the number of times they had read each target item or the number of times they had generated each target item. Generating items systematically increased the frequency estimates for the seen items, and item presentations systematically increased the estimates for the generated items. The former effect was greater than the latter. Indeed, when subjects were not given a limit for their frequency estimates, Raye et al. (1980) found that "the number of times subjects generated items had a large effect on their judgments of presentation frequency, actually contributing more than presentations" (p. 145).

Although one must be very cautious in contrasting the magnitude of effects between different experiments, a comparison of Raye et al.'s results and the present findings suggests that subjects have greater difficulty in distinguishing between seen and generated items than between single-item and word-pair presentations. This difference is consistent with the assumption that item and associative information represent different types of memorial information.
The present finding that frequency judgments for words may not be limited only to single-item presentations but can also include occurrences of the item in word pairs (Experiment 6) and the finding that frequency judgments can include items that appeared as members of different word pairs (Experiment 7) indicate that contextual or source information does not overly constrain retrieval of item information. That is, the use of contextual information in item recognition appears to have an optional, rather than an obligatory, quality. This may, at least partially, explain why the effects of environmental context that are generally found in tests of recall have been so difficult to obtain with tests of recognition (e.g., Smith, 1988). Context may be used if it is helpful or required by the task but may be ignored if it is not necessary.

The assumption that the use of contextual information is optional is consistent with the source-monitoring framework of Johnson et al. (1993). In their view, "people do not typically directly retrieve an abstract tag or label that specifies a memory's source, rather, activated memory records are evaluated and attributed to particular sources through decision processes performed during remembering" (p. 3).

\section{Global Matching Models}

The present study was initially designed to provide a test of the retrieval assumptions of global matching models of recognition memory, and the results have several implications for models of this class. First, the results are problematic for TODAM. In this model, it is assumed that item and associative information are separately encoded and retrieved. This leads to the prediction that frequency judgments for word pairs should not be influenced by the frequency of item information. The present results, however, show that there is a small, but systematic and reliable, effect of overlapping singleton and pair presentations on frequency judgments for pairs.

It is also generally assumed in TODAM that both item and associative information are encoded when an association between two words is formed, although the relative amounts of each type of information can vary. Thus, TODAM could account for the present finding that subjects can estimate the total frequency of item occurrences by assuming that sufficient item information is encoded when word pairs are presented. However, TODAM could then not account for the ability of subjects to limit their frequency judgments for words to singleton presentations. Neither the original formulation of TODAM (Murdock, 1982) nor a more general version of the model (TODAM2; Murdock, 1993) include context information, and thus these versions of the model have no mechanism to differentiate between item information encoded from singleton and word-pair presentations.

Murdock (in press) has recently developed a revised version of TODAM2. The modifications involve embedding item and associative information in context. For item information, context elements are added to the item vectors and autoassociation is used to bind the items to their context. For associative information, the item vec- 
tors are summed before context is added and autoassociation is again used to bind the association to its context. As item information is included in associative information, there are two bases for item recognition, and item information can be distinguished on the basis of contextual information. Thus, this version of TODAM2 may be able to account for the ability of subjects to distinguish between items presented singly and items presented as members of different word pairs.

The present results are also problematic for the SAM model, if it is assumed that frequency judgments are based on strength or familiarity. ${ }^{2}$ In this model, item and associative information both contribute to the retrieved familiarity values calculated for item and associative test probes. Such an assumption leads to the prediction that presenting items both as singletons and as members of word pairs would increase the familiarity value of both the single words and the word pairs.

In the original version of SAM, associations are represented as links between separately stored items in the memory matrix. Clark (1995) refers to this formulation of SAM as the item-level association (ILA) model. In a second version of SAM, introduced by Shiffrin, Murnane, Gronlund, and Roth (1988), associations are represented as higher order units that are separate from the items that make up the associations. Clark (1995) refers to this version as the higher order association (HOA) model. In an analysis of the generation effect, Clark (1995) showed that the HOA model provides a better and more parsimonious fit than the ILA model. The present finding that subjects can, to a considerable degree, distinguish the frequency of single words and word pairs provides further support for the HOA version of SAM. The HOA model as described by Clark cannot, however, explain the small, but reliable, effects of single-word presentations on estimates of word-pair frequency, because item and associative information are stored separately at different levels in memory.

In the HOA model, context information at the item level could provide the basis for distinguishing between words encoded as singletons and words studied as members of pairs. As Smith, Glenberg, and Bjork (1978) have noted, "context" is a rather vague concept that includes aspects of the physical environment and the subject's internal mental state. Thus, it is not clear how specific contextual information can be. But if memory could be cued both with and without "included-in-pair" context, then subjects could differentiate between words presented singly and as members of word pairs, and these two retrieval outcomes could be added to give a combined frequency estimate.

In MINERVA 2, each occurrence of an item is represented by a separate memory trace and each word pair is represented by the concatenation of the two item vectors. The memory traces contain both content and context features. Frequency estimates for word pairs would be largely based on the match between the test pair and the number of traces of that pair in memory. Members of the pair studied as single items would contribute to the famil- iarity value of the match because they would provide a partial match to the test probe. The contribution of these partial matches would, though, be much smaller in magnitude, because they would also differ in terms of their context features. In the same way, frequency judgments for single-word presentations would largely be based on the match between the single-word probe and the number of traces of that single word in memory. Memory traces of word pairs that contain the single word as a member would contribute to the familiarity of the single word, but to a lesser extent because of the differences in context.

Hintzman (1988) has also used an intertrace resonance process to magnify or heighten the role of contextual similarity. Using the "echo-probe conversion" algorithm (Hintzman, 1986), the echo triggered by the initial probe is then used as a secondary memory probe. The secondary probe includes both content and contextual features. The intensity of the echo from the secondary probe is added to the intensity of the first echo to represent the combination of activation due to the probe and intertrace resonance. Hintzman (1988) showed that, by adding the intertrace resonance process, MINERVA 2 can predict greater frequency judgments for words repeated in the same context than for words repeated in different contexts. In the same manner, intertrace resonance would also serve to help MINERVA 2 restrict frequency judgments to singleitem or word-pair presentations.

MINERVA 2 would predict that when frequency judgments are based on the total number of occurrences of words irrespective of context, the single-item presentations should contribute more to the familiarity of the singleitem test probe than would items that were studied as members of word pairs. This is because the memory traces of the single item would provide a better match to the singleitem probe than would the memory traces of concatenated pairs of items. The results of Experiment 5, however, showed that frequency estimates for the total number of item presentations were sensitive to occurrences of items both as singletons and as members of word pairs to a similar extent.

\section{Summary}

The present study provides further evidence for the distinction between item and associative information in memory. When words were presented singly and in pairs, subjects could distinguish between the frequencies of singleton and word-pair presentations. Although judgments were largely based on the appropriate frequencies, discrimination was not perfect. This pattern of results is inconsistent with models that do not distinguish between item and associative information at retrieval, such as the ILA version of SAM, and is problematic for models that impose too strict a dichotomy between item and associative information such as the versions of TODAM and the HOA implementation of SAM.

Subjects could also accurately judge the combined frequency of words shown both singly and in word pairs, and subjects could accurately judge the total frequency of words presented as members of different word pairs. 
These results, together with the results just described above, indicate that the encoding of associative information also entails the encoding of item information, and that while contextual information can be used to largely restrict frequency judgments for words to singleton presentations, contextual differences can also be ignored when necessary. These findings are consistent with the source-monitoring framework of Johnson et al. (1993), in which it is assumed that source attributions are based on an assessment of the characteristics of the memories at retrieval.

The present findings thus provide further evidence for the distinction between item and associative information, and illustrate the optional use of contextual information at retrieval. More generally, the results demonstrate that a variety of information is encoded for a studied event and that there is a great degree of flexibility in how this information is retrieved.

\section{REFERENCES}

ANDERSON, J. R., \& BowER, G. H. (1974). Interference in memory for multiple contexts. Memory \& Cognition, 2, 509-514.

BegG, I., Maxwell, D., Mitterer, J. O., \& Harris, G. (1986). Estimates of frequency: Attribute or attribution? Journal of Experimental Psychology: Learning, Memory, \& Cognition, 12, 48-54.

CLARK, S. E. (1992). Word frequency effects in associative and item recognition. Memory \& Cognition, 20, 231-243

CLARK, S. E. (1995). The generation effect and the modeling of associations in memory. Memory \& Cognition, 23, 442-455.

Clark, S. E., \& BURChetT, R. E. R. (1994). Word frequency and list composition effects in associative recognition and recall. Memory $\&$ Cognition, 22, 55-62.

ClaRK, S. E., \& ShIfFrin, R. M. (1992). Cuing effects and associative information in recognition memory. Memory \& Cognition, 20, 580-598.

DOSHER, B. A. (1988). Retrieval dynamics of item and associative information. Unpublished manuscript.

EICHENBAUM, H., \& BUNSEY, M. (1995). On the binding of associations in memory: Clues from studies on the role of the hippocampal region in paired-associative learning. Current Directions in Psychological Science, 4, 19-23.

Gillund, G., \& Shiffrin, R. M. (1984). A retrieval model for both recognition and recall. Psychological Review, 91, 1-67.

GRonLUND, S. D., \& RaTCLIFF, R. (1989). Time course of item and associative information: Implications for global memory models. Journal of Experimental Psychology: Learning, Memory, \& Cognition, 15, 846-858.

HASHER, L., \& ZACKS, R. T. (1984). Automatic processing of fundamental information: The case of frequency of occurrence. American Psychologist, 39, 1372-1388.

HintzMAN, D. L. (1984). MINERVA 2: A simulation model of human memory. Behavior Research Methods, Instruments, \& Computers, 16, 96-101.

HintzMan, D. L. (1986). "Schema abstraction" in a multiple-trace memory model. Psychological Review, 93, 411-428.

Hintzman, D. L. (1988). Judgments of frequency and recognition memory in a multiple-trace memory model. Psychological Review, 95, 528-551.

Hintzman, D. L., \& Block, R. (1971). Repetition and memory: Evidence for a multiple-trace hypothesis. Journal of Experimental Psychology, 88, 297-306.

HintzMan, D. L., \& Block, R. (1973). Memory for the spacing of repetitions. Journal of Experimental Psychology, 99, 70-74.

Hintzman, D. L., Block, R., \& Summers, J. J. (1973). Modality tags and memory for repetitions: Locus of the spacing effect. Journal of Verbal Learning \& Verbal Behavior, 12, 229-238.
Hintzman, D. L., Curran, T., \& Caulton, D. A. (1995). Scaling the episodic familiarities of pictures and words. Psychological Science, 6, 308-313.

Hintzman, D. L., Curran, T., \& OPPY, B. (1992). Effects of similarity and repetition on memory: Registration without learning? Journal of Experimental Psychology: Learning, Memory, \& Cognition, 18, 667-680. HinTZMAN, D. L., \& HARTRY, A. L. (1990). Commensurability in memory for frequency. Journal of Memory \& Language, 29, 501-523.

Hock, H. S., Malcus, L., \& Hasher, L. (1986). Frequency discrimination: Assessing global-level and element-level units in memory. Journal of Experimental Psychology: Learning, Memory, \& Cognition, 12, 232-240.

HoCKLEY, W. E. (1991a). Interrogating memory: A decision model for recognition and judgment of frequency. In W. C. Abraham, M. C. Corballis, \& K. G. White (Eds.), Memory mechanisms: A tribute to G. V. Goddard (pp. 219-245). Hillsdale, NJ: Erlbaum

HOCKLEY, W. E. (1991b). Recognition memory for item and associative information: A comparison of forgetting rates. In W. E. Hockley \& S. Lewandowsky (Eds.), Relating theory and data: Essays on human memory in honor of Bennet B. Murdock (pp. 227-248). Hillsdale, NJ: Erlbaum.

HOCKLEY, W. E. (1992). Item versus associative information: Further comparisons of forgetting rates. Journal of Experimental Psychology: Learning, Memory, \& Cognition, 18, 1321-1330.

HOCKLEY, W. E. (1994). Reflections of the mirror effect for item and associative recognition. Memory \& Cognition, 22, 713-722.

HocklEY, W. E., \& CRISTI, C. (1996). Tests of encoding tradeoffs between item and associative information. Memory \& Cognition, 24, 202-216.

Humphreys, M. S., Pike, R., Bain, J. D., \& Tehan, G. (1989). Global matching: A comparison of SAM, MINERVA II, Matrix, and TODAM models. Journal of Mathematical Psychology, 33, 36-67.

Johnson, M. K., Hashtroud, S., \& LindSAY, D. S. (1993). Source monitoring. Psychological Bulletin, 114, 3-28.

Johnson, M. K., \& RAYE, C. L. (1981). Reality monitoring. Psychological Review, 88, 67-85.

Johnson, M. K., Raye, C. L., Foley, H. J., \& Foley, M. A. (1981). Cognitive operations and decision bias in reality monitoring. American Journal of Psychology, 94, 37-64.

JoHnSON, M. K., TAYLOR, T. H., \& RAYE, C. L. (1977). Fact and fantasy: The effects of internally generated events on the apparent frequency of externally generated events. Memory \& Cognition, 5, 116-122.

KePPEL, G. (1991). Design and analysis: A researcher's handbook (3rd ed.). Englewood Cliffs, NJ: Prentice-Hall.

MURDOCK, B. B., JR. (1982). A theory for the storage and retrieval of item and associative information. Psychological Review, 89, 609626.

Murdock, B. B. (1993). TODAM2: A model for the storage and retrieval of item, associative, and serial-order information. Psychological Review, 100, 183-203.

MuRDOCK, B. B. (in press). Item and associative information in TODAM2. Psychological Review.

Murdock, B. B., \& HockLEY, W. E. (1989). Short-term memory for associations. In G. H. Bower (Ed.), The psychology of learning and motivation (Vol. 24, pp. 71-108). San Diego, CA: Academic Press.

Paivio, A., Yuille, J. C., \& Madigan, S. A. (1968). Concreteness, imagery, and meaningfulness values for 925 nouns. Journal of Experimental Psychology Monographs, 76(1, Pt. 2), 1-25.

RaAiJmakers, J. G., \& Shiffrin, R. M. (1981). Search of associative memory. Psychological Review, 88, 93-134.

Raye, C. L., Johnson, M. K., \& TAYlor, T. H. (1980). Is there something special about memory for internally generated information? Memory \& Cognition, 8, 141-148.

Shiffrin, R. M., Murnane, K., Gronlund, S. D., \& Roth, M. (1988). On units of storage and retrieval. In C. Izawa (Ed.), Current issues in cognitive processes: The Tulane-Floweree Symposium on Cognition (pp. 25-68). Hillsdale, NJ: Erlbaum.

SMITH, S. M. (1988). Environmental context-dependent memory. In D. M. Thomson \& G. M. Davies (Eds.), Memory in context: Context in memory (pp. 13-34). New York: Wiley. 
Smith, S. M., GlenberG, A. M., \& BJork, R. A. (1978). Environmental context and human memory. Memory \& Cognition, 6, 342-353.

\section{NOTES}

1. Effect size was calculated by estimating omega squared, which is a proportional measure of the variation accounted for by the treatment manipulation in an experiment (Keppel, 1991, pp. 62-68).

2. SAM has not been applied to judgments of frequency. Although some investigators have argued that memory for frequency enjoys a spe- cial or privileged status (e.g., Hasher \& Zacks, 1984), a more general consensus is that judgments of event frequency are based on the same information that supports recognition decisions (see, e.g., Begg, Maxwell, Mitterer, \& Harris, 1986; Hintzman, 1988). Moreover, Hintzman and his colleagues (Hintzman, Curran, \& Caulton, 1995; Hintzman, Curran, \& Oppy, 1992; Hintzman \& Hartry, 1990) have provided direct evidence for the commensurability of recognition and frequency judgments. As Hintzman (1988) has used this assumption to model both recognition and frequency judgments in MINERVA 2, and Hockley (1991a) used a similar approach for TODAM, the same assumption is adopted here for SAM.

\section{APPENDIX A}

In the table below are the linear slope values of the mean frequency estimates as a function of the different frequency manipulations in the disjoint conditions of Experiments 3, 4, and 6. The slopes of the mean estimates for word tests are given as a function of singleton presentation frequency at each level of pair frequency and as a function of pair frequency at each level of singleton frequency. In the same fashion, the slopes of the mean estimates for word pairs are given as a function of singleton frequency at each level of pair frequency and as a function of pair frequency at each level of singleton frequency.

\begin{tabular}{ccccccc}
\hline & & \multicolumn{2}{c}{ Words } & & \multicolumn{2}{c}{ Pairs } \\
\cline { 3 - 4 } \cline { 6 - 7 } Experiment & Frequency & Singleton & Pair & & Singleton & Pair \\
\hline 3 & 1 & .51 & .07 & & .11 & .81 \\
& 2 & .50 & .18 & & .15 & .77 \\
& 4 & .51 & .10 & & .03 & .67 \\
& Mean & .51 & .12 & & .10 & .75 \\
4 & 1 & .49 & .12 & & .13 & .77 \\
& 2 & .47 & .09 & & .16 & .79 \\
& 3 & .44 & .07 & & .11 & .76 \\
& Mean & .47 & .09 & & .13 & .77 \\
6 & 1 & .45 & .48 & & .10 & .57 \\
& 2 & .45 & .49 & & .28 & .68 \\
& 3 & .51 & .54 & & .25 & .72 \\
& & .47 & .50 & & .21 & .65 \\
\hline
\end{tabular}

\section{APPENDIX B}

In the table below are given the linear slopes of the mean frequency estimates for each type of test probe as a function of joint-pair frequency for each level of semijoint frequency and as a function of semijoint frequency for each level of joint-pair frequency for the disjoint conditions of Experiments 5 and 7.

\begin{tabular}{|c|c|c|c|c|c|c|c|}
\hline \multirow[b]{2}{*}{ Experiment } & \multirow[b]{2}{*}{ Frequency } & \multicolumn{2}{|c|}{ Words } & \multicolumn{2}{|c|}{ Joint Pairs } & \multicolumn{2}{|c|}{ Semijoint Pairs } \\
\hline & & Joint & Semijoint & Joint & Semijoint & Joint & Semijoint \\
\hline \multirow[t]{4}{*}{5} & 1 & & & .77 & .23 & .04 & .81 \\
\hline & 2 & & & .65 & .29 & .14 & .73 \\
\hline & 3 & & & .71 & .17 & .02 & .79 \\
\hline & Mean & & & .71 & .23 & .07 & .78 \\
\hline \multirow[t]{4}{*}{7} & 1 & .59 & .54 & 1.10 & .23 & 1.00 & -.08 \\
\hline & 2 & .65 & .69 & 1.00 & .36 & 1.20 & -.15 \\
\hline & 3 & .49 & .44 & .93 & .11 & 1.20 & .15 \\
\hline & Mean & .58 & .56 & 1.01 & .23 & 1.13 & -.03 \\
\hline
\end{tabular}

